\title{
Vocabulary Proficiency Instruction for Chinese EFL Learners*
}

\author{
Ruixue Ma \\ Dalian University of Technology, Dalian, China \\ Email: maruixue@dlut.edu.cn
}

\begin{abstract}
Vocabulary learning is a headache for many Chinese EFL learners and vocabulary teaching remains a challenge for Chinese EFL teachers. The paper lists the problems involved in the traditional vocabulary teaching and learning mode. Traditional teaching mode put more emphasis on mechanical memorization to enlarge students' vocabulary instead of developing their lexical competence. Students have inadequate vocabulary learning strategies, low motivation, no collaborative learning environment to practice their lexical competence, insufficient exposure to authentic language input, inadequate teachers' instruction on social strategies. This paper analyzes the reasons that lead to the current problems. Aiming at solving the above-mentioned problems with traditional instruction mode, the research proposes a multi-dimensional instruction mode with lexical competence development as its goal, digital technology as its media, task-based learning and collaborative learning as its form, campus English native speakers as its resources, textbooks as its content. An empirical study was made to test the effectiveness of the proposed mode, results of which prove mode to be effective in increasing the students' receptive vocabulary size, productive vocabulary richness and awareness of using strategy learning strategies and motivation.
\end{abstract}

Index Terms - lexical proficiency instruction, vocabulary learning strategy, Chinese EFL learners, data-driven learning, task-based teaching, an empirical study

\section{INTRODUCTION}

Vocabulary is not only an obstacle but also a challenge to English teaching and learning. The lexical significance in second language learning and teaching has been repeatedly acknowledged in theoretical and empirical second language acquisition (SLA) vocabulary research. Researchers have described the powerful, positive relationship between vocabulary and comprehension (Anderson \& Freebody, 1981; Davis, 1944). No matter how well the student learns grammar, no matter how successfully the sounds of L2 are mastered, without words to express a wide range of meanings, communication in an L2 just cannot happen in any meaningful way (McCarthy, 1990). Meara (1996) argues that learners with big vocabularies are more proficient in a wide range of language skills than learners with smaller vocabularies, and there is some evidence to support the view that vocabulary skills make a significant contribution to almost all aspects of L2 proficiency. Sufficient vocabulary size is a prerequisite for becoming competent language learners.

There is a great necessity to analyze the problems involved in traditional Chinese lexical proficiency instruction and propose constructive solutions to the problems.

\section{Statement of the Problems}

Firstly, many Chinese EFL learners often feel frustrated with remembering English words, and they have inadequate vocabulary learning strategies. Their vocabulary breadth knowledge or vocabulary size and vocabulary depth knowledge are extremely small. Under traditional teaching mode teachers put more emphasis on mechanical memorization without realizing the importance and necessity of equipping students with vocabulary learning strategies.

Moreover, even though they are able to remember some words, they cannot use them in authentic language context correctly and appropriately. The learners' receptive and productive vocabulary sizes are severely out of balance. The inadequate ability of using the language in authentic world is due to the problems of traditional EFL teaching system. Students have been facing pressure of English written exams ever since they started learning English. They are facing entrance exams for junior high schools, senior high schools, universities, graduate admission exams, PhD entrance exams. Even after graduation there are English exams for a promotion. Almost none of these important English exams include productive lexical competence evaluation. Consequently English teachers adopt teaching approaches no more than grammar translation and audio-lingual methods with emphasis on accuracy of grammar, neglecting the communicative goal of vocabulary learning.

\footnotetext{
* The research is supported by "the Fundamental Research Funds for the Central Universities" Number: (DUT11RW412) and "Liaoning Social Science Fund" Number (L11DYY032).
} 


\section{METHOD}

\section{A. Objective of the Research}

The purpose of the present study is twofold. On the one hand, based on the theory framework the research proposes a multi-dimensional lexical proficiency instruction mode with digital video as its media and task-based collaborative learning as its form, campus English native speakers as its resources, textbooks as its content. On the other hand, an empirical study is designed to prove the effectiveness of the proposed mode. The present study seeks to find appropriate answers to the following research questions:

1) Are there any differences in the lexical proficiency competences between the experimental group under the instruction mode proposed in this study and control groups under traditional instruction mode?

2) Are there any differences in vocabulary learning strategies levels between the experimental group under the instruction mode proposed in this study and control groups under traditional instruction mode?

The above questions led the researchers of the present study to propose the following hypotheses:

H1. The lexical proficiency competences of the experimental group under the instruction mode proposed in this study is higher than that of the control group under traditional instruction mode.

$\mathrm{H} 2$. The vocabulary learning strategies levels of the experimental group under the instruction mode proposed in this study is higher than that of the control group under traditional instruction mode.

\section{B. Multi-dimensional Lexical Proficiency Instruction Mode Proposed in this Research}

Any single lexical pedagogy cannot effectively enhance the vocabulary instruction efficiency. Effective instruction mode should resort to a combination of various approaches. Based on the theory framework the research proposes a multi-dimensional lexical proficiency instruction mode with digital technology as its media, task-based learning and cooperative learning as its form, campus English native speakers as its resources, and textbooks as its content.

\section{Resort to captioned video to enrich the channels of language input}

Current form of language input is dull and monotonous. To solve this problem, captioned movie is applied in the instruction mode proposed in this research. Several studies indicate the effectiveness of captioned videos in improving students' vocabulary learning aptitude.

Several principles should be followed while choosing the captioned movies. Firstly the selected movie should suit the level and interests of the students so that the students can be highly motivated in their vocabulary learning. Secondly the video should be previewed so that the right segment most closely related to themes and vocabularies of the textbook can be located. Thirdly, the clip should be kept within 5 minutes without occupying much of the normal instruction period.

Here is a real case from the none-English majors' English course. The story in the textbook is A Test of True Love, the main plot of which is as follows:

John Blandford volunteered for military service 13 months ago. Soon he received a book from Hillis Meynell, a woman who sent everyone in the military service a book, strength and her support for their cause. He wrote back, and thus went into connection with her. For thirteen months, she wrote and gave him courage to survive. After a short time, he believed that they loved each other and that fate had brought them together. But, she declined his request of her photo. Now the soldier was back in New York, waiting to meet her in person at the information desk in Grand Central Station, and a young girl in good figure was coming in his direction, but without a red rose as they planned. When he invited the fat woman with the rose to dinner, it turned out to be a test of Hollis Meynell, and he passed it.

The captioned movie Beauty and Beast was chosen as the warming up lead-in activity in the teaching process. The prologue at the very beginning of the movie was selected:

"Once upon a time, in a faraway land, a young Prince lived in a shining castle. Although he had everything his heart desired, the Prince was spoiled, selfish, and unkind. But then, one winter's night, an old beggar woman came to the castle and offered him a single rose In return for shelter from the bitter cold. Repulsed by her haggard appearance, the Prince sneered at the gift, and turned the old woman away. But she warned him not to be deceived by appearances, for Beauty is found within. And when he dismissed her again, the old woman's ugliness melted away to reveal a beautiful Enchantress. The Prince tried to apologize, but it was too late, for she had seen that there was no love in his heart. And as punishment, she transformed him into a hideous beast, and placed a powerful spell on the castle, and all who lived there. Ashamed of his monstrous form, the Beast concealed himself inside his castle, with a magic mirror as his only window to the outside world. The Rose she had offered was truly an enchanted rose, which would bloom for many years. If he could learn to love another, and earn her love in return by the time the last petal fell, then the spell would be broken. If not, he would be doomed to remain a beast for all time. As the years passed, he fell into despair, and lost all hope, for who could ever learn to love a Beast?"

The 2-minute prologue was used as a lead-in of the lesson, in which the students were asked to watch the movie and then guess out the meaning of the underlined words with the help of the context. This multimedia-based input provided the students with multisensory presentation of information, which captured the students' attention and stimulated students' motivation to learn. And with the semantically rich context, the acquisition of lexical skills naturally happens.

\section{Resort to SBI to develop students' vocabulary learning strategies}

In his SBI theory Cohen (2000) proposed that strategy training should be integrated into the classroom language teaching. With limited classroom time, college English teachers find it really challenging to insert training vocabulary 
learning strategies into language teaching process. However if teachers could make a perfect combination of explicit and implicit instruction, the SBI mode can greatly enhance the classroom teaching efficiency. For example, the strategy of "Use the newly-learnt English words I know in different ways." is frequently introduced to the students in a way of explicit explanation. But that's far from enough. In order to strengthen the students' impression of this strategy and to stimulate their motivation to apply it, teachers should set models by personally practicing it. In the following statement the teacher used the underlined newly-learnt vocabularies from the textbook to make comments on the students' classroom presentation and encourage them to make further efforts and progress.

Dear Students:

More and more students had experienced how it feels to stand on the stage as a teacher. Despite the challenges, worries and distress, the chance really brought you a lot more than language improvement, which can by no means be acquired from conventional teaching.

I can not help saying that "How marvelous you are". Given that you've never made public speech in the presence of large audience, I should assert that you've really done a superb job. I can perceive that most of the "amateur teachers" had racked up the brain to devise amusing, efficient and creative classroom activities, which result in lots of interaction between students and teachers.

Reflecting on how everything is going in the previous month, we can not deny that there is more to be poured into our teaching than merely temporary passion to guarantee a promising future.

For example, the assessment system needs to be scientifically and designed and strictly carried out to ensure the students' good preparation of each lesson in advance and active participation inside class.

My dear student, college life is when we should have the courage, heart, and discipline to persist, even if it takes a billion tries. Let's enjoy our college life by overcoming the obstacles one after another.

In the above example the teacher achieved the integration of vocabulary learning strategies into classroom teaching implicitly, which overcome the obstacle of inadequate classroom time for strategy instruction.

3. Motive the students to develop their productive vocabulary competence in authentic context.

Adequate production of high quality language is a precondition for EFL learners to become competent lexical learners. However, with the exam-oriented teaching system and Chinese cultural concepts of "saving face" and "avoiding showing off" students seldom practice English in public. Learners lack target language environment. Students are learning in a foreign language context where the target language is not the language of communication in the society.

In the proposed mode in this research the students are required to make friends with English native speakers on campus and invite their foreign friends to complete the assignments like interviewing foreign teachers or helping overseas students go shopping. The students are required to use digital video camera to record their process doing their extracurricular homework and bring the clip into classroom for comments of the teacher and classmates on their vocabulary competence and application of vocabulary learning strategies in the real situation.

4. Resort to the form of task-based learning (TBL) and collaborative learning (CL).

In the proposed mode of the research, the students are required to form a team of 3-4 members and work collaboratively to complete the extracurricular tasks. The tasks can be a drama play in which the students work together to find an appropriate script and rehearse the roles hoping to be greatly acknowledged by their classmates. Task can also appear in the form of contact assignment like interview of foreigners. Kathleen M. Bailey (2004) refers such tasks as contact assignment.

5. Resort to DDL or CALL to enhance the teaching efficiency

\subsection{The application of DDL to present authentic context of the words}

Wang Y\&Yang J. (2008) said that DDL (Data-driven Learning) is a teaching paradigm based on the application of the corpus and the researches in language acquisition and cognitive science, whereas lexical approach stresses the necessity of using corpora in pedagogical materials and the importance of regularly recycling and reviewing the language taught. Data-driven Learning can be combined with lexical approach to improve the lexis instruction in the second language. Teubert (2005) pointed out that corpus is considered the default resource for almost anyone working in linguistics. No introspection can claim evidence without verification through real language data. Corpus research has become a key element of almost all language study.

The following example is the KWIC list of the word "deny" provided by Corpus of Contemporary American English (COCA) that is created by Prof.Mark Davies. This corpus contains 420 million words of the materials published in America from 1990 to 2011, and it is the largest balanced English corpus. The Corpus of Contemporary American English is free for researchers and English learners to use online. 


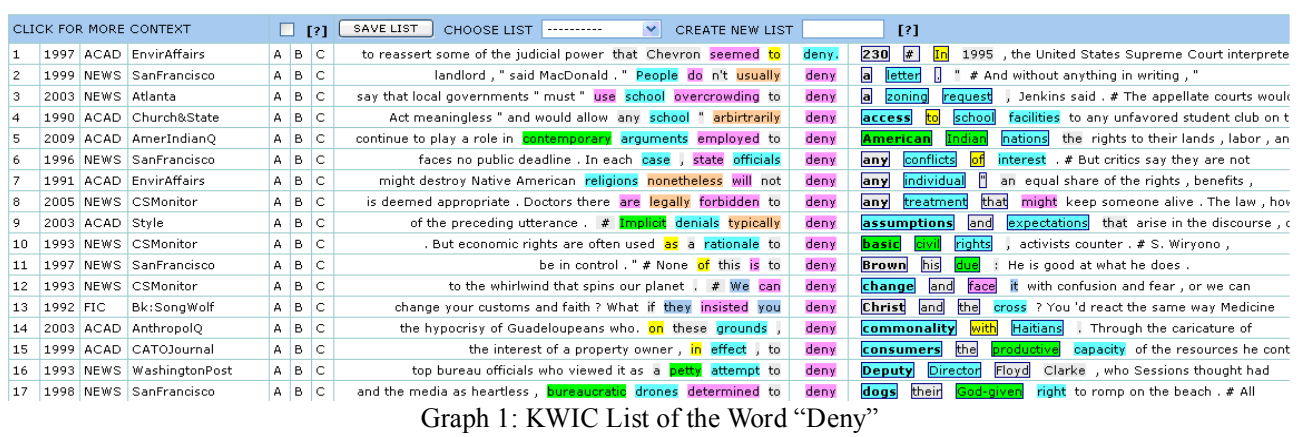

The KWIC (key word in context) list in Graph 1 reveals the collocations (words that co-occur regularly), colligations (grammatical patterns that co-occur regularly) of the lexical item of "deny". Meanwhile it also reveals the target word of "deny" in authentic context. DDL equips EFL teachers an efficient tool to help students to discover lexical meaning, understand the use of the word and notice the patterns that surround it.

5.2 The application of CALL to diversify the forms of exercises

Computer-assisted Language Learning (CALL) is succinctly defined in a seminal work by Levy (1997) as "the search for and study of applications of the computer in language teaching and learning"(p.1).

Teachers should learn to make full use of information technology to enhance the teaching efficiency. For example, free online software can help us design crossword puzzle game to test the students' memorization of new vocabularies. All you need to do is to give the words and their clues, and the online software will give you the puzzle automatically. Graph 2 is an example made by the free online puzzle maker (http://www.armoredpenguin.com/crossword/).
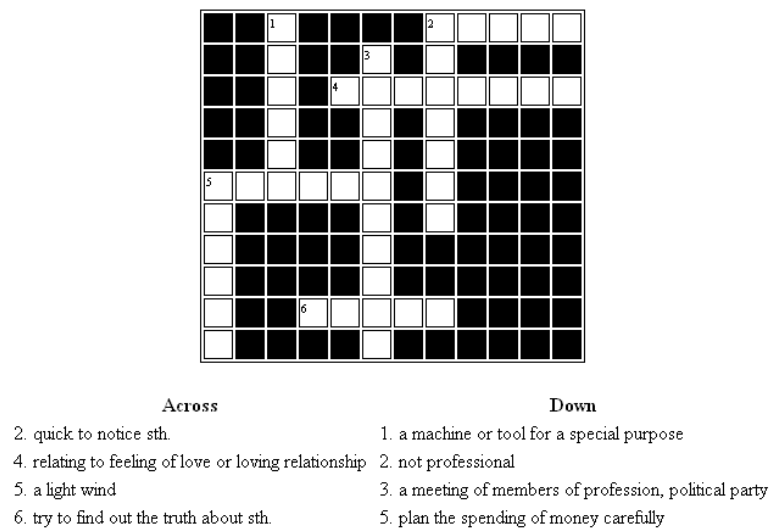

Graph 2: A Crossword Puzzle Designed by Online Crossword Online Maker

\section{(1). Participants}

The present study focuses on the effectiveness of the vocabulary instruction mode proposed by this research and was conducted at Dalian University of Technology, Peoples' Republic of China. The subjects are 70 EFL learners who are all none English majors undergraduates, with 35 in the experimental group, while 35 in the control group.

\section{(2). Instruments}

(2.1) Tests assessing receptive vocabulary size

Multiple choice tests are designed to assess the students' vocabulary size to before and after the research.

\section{(2.2) Tests assessing productive vocabulary richness}

The students are required to deliver a speech about 500 words on similar topics before and after the research. The speeches are recorded and transcribed into text for Standardized TTR analysis.

TTR is number of different words in a text divided by the number of running words. The type-token ratio (TTR) is a measure of vocabulary variation within a written text or a person's speech. The type-token ratio is shown to be a helpful measure of lexical variety within a text (Williamson, G., 2009). But TTR may vary a lot according to the different lengths of a text, so it is not meaningful to compare TTRs for texts of different lengths. Therefore Standardized TTR is used in this research. Standardized TTR is the average of the TTR for each sequence of $n$ words (typical default $n=1000$ ) in a text or corpus.

\section{(2.3) A questionnaire for surveying students' use of vocabulary learning strategies}

It is hypothesized that learning problems may mainly result from learners' use of learning strategies. The questionnaire used for the survey of students' vocabulary learning strategies is revised from the SILL questionnaire (Strategies Inventory of Language Learning) by Rebecca Oxford (1990). There are altogether 18 vocabulary learning strategies classified into 3 categories, namely memory strategy, cognitive strategy and compensation strategy.

The questionnaire is based on a five-point Likert scale from 1 to 5, in which 1 represents "totally or almost totally 
unsuitable for me"; 2 represents "suitable for me less than half of the time"; 3 represents "suitable for me about half of the time"; 4 represents "suitable for me more than half of the time"; 5 represents "totally or almost totally suitable for me". For example:

$1=$ totally or almost totally unsuitable for me

$2=$ suitable for me less than half of the time

$3=$ suitable for me about half of the time

$4=$ suitable for me more than half of the time

$5=$ totally or almost totally suitable for me

TABLE 1:

THE SAMPLE OF THE QUESTIONNAIRE:

\begin{tabular}{|c|c|c|c|c|c|c|}
\hline & Vocabulary Strategies & 1 & 2 & 3 & 4 & 5 \\
\hline \multirow{6}{*}{ 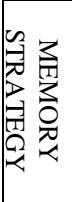 } & 1. I think of relationships between the words I already know and new words I learn in English. & & & & & \\
\hline & 2. I remember a new English word by making a mental picture of a situation in which the word might be used. & & & & & \\
\hline & 3. I connect the sound of a new English word and an image or picture of the word to help me remember the word. & & & & & \\
\hline & 4. I use new English words in a sentence so I can remember them. & & & & & \\
\hline & 5. I use rhymes to remember new English words. & & & & & \\
\hline & 6. I physically act out new English words. & & & & & \\
\hline \multirow{6}{*}{ 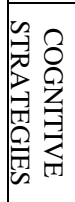 } & 1. I first skim an English passage then go back and read carefully. & & & & & \\
\hline & 2. I try not to translate word-for word. & & & & & \\
\hline & 3. I try to talk like native English speakers. & & & & & \\
\hline & 4. I use the English words I know in different ways. & & & & & \\
\hline & 5. I read for pleasure in English. & & & & & \\
\hline & 6. I make summaries of information that I hear or read in English. & & & & & \\
\hline \multirow{6}{*}{ 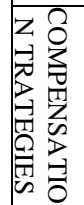 } & 1. To understand unfamiliar English words, I make guesses. & & & & & \\
\hline & 2. When I can't think of a word during a conversation in English, I use gestures. & & & & & \\
\hline & 3. I read English without looking up every new word. & & & & & \\
\hline & 4. I try to guess what the other person will say next in English. & & & & & \\
\hline & 5. If I can't think of an English word, I use a word or phrase that means the same thing. & & & & & \\
\hline & 6. I make up new words if I do not know the right ones in English. & & & & & \\
\hline
\end{tabular}

\section{RESULTS AND ANALYSIS}

The experiment lasted for one semester. The experimental group and control group were given instruction respectively under the multi-dimensional mode proposed in this research and traditional mode. Tests and survey were given before and after the research as quantitative measure and interview were given to them as qualitative measure to improve the reliability and validity of the study. SPSS 17.0 was used for statistical analysis.

\section{Receptive vocabulary size tests result analysis}

Firstly, paired-samples t-test was used to examine the vocabulary size tests results of the experimental group and control group before and after the experiment. The results in Table 2 show that the experimental group made significant progress in the speaking ability (sig=.000), while the control group didn't make any significant progress $(\mathrm{sig}=.101)$.

TABLE 2:

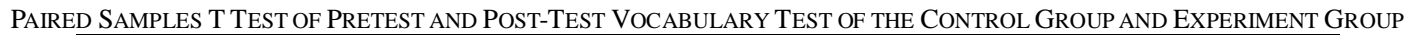

\begin{tabular}{|c|c|c|c|c|c|}
\hline & Mean(Pre-Post) & $\mathrm{N}$ & $\bar{t}$ & $\mathrm{df}$ & Sig(2-tailed) \\
\hline Experimental Group & $72.5429-80.6571$ & 35 & -14.119 & 34 & $.000 * *$ \\
\hline Control Group & $72.0857-74.9143$ & 35 & -1.688 & 34 & .101 \\
\hline
\end{tabular}

\section{Productive vocabulary richness tests result analysis}

Secondly, paired-samples t-test was used to examine the vocabulary richness tests results of the experimental group and control group before and after the experiment. The results in Table 3 show that the experimental group made significant progress in the vocabulary richness (sig=.015), while that of the control group was not significant progress $(\operatorname{sig}=.086)$.

TABLE 3:

PAIRED SAMPLES T TEST OF PRETEST AND POST-TEST TTR OF THE CONTROL GROUP AND EXPERIMENT GROUP

\begin{tabular}{|c|c|c|c|c|c|}
\hline & Mean(Pre-Post) & $\mathrm{N}$ & $\mathrm{t}$ & df & Sig(2-tailed) \\
\hline Experimental Group & $0.6874-0.7229$ & 35 & -2.572 & 34 & $.015 *$ \\
\hline Control Group & $0.6897-0.6963$ & 35 & -1.771 & 34 & .086 \\
\hline
\end{tabular}

\section{Vocabulary learning strategy application survey result analysis}

70 valid questionnaires for a survey of the vocabulary learning strategy application before and after the research were collected after the class visit. Paired samples t-test was used to analyze the results. Statistics in Table 4 show that students in the experimental group make significant improvement in their application of all of the three categories of 
vocabulary learning strategies: memory strategy $(\mathrm{sig}=.000)$; cognitive strategy $(\mathrm{sig}=.000)$ and compensation strategy (sig=.001). While Table 5 shows that the progress of the control group is not significant: memory strategy (sig=.945); cognitive strategy $(\mathrm{sig}=.558)$ and compensation strategy $($ sig=.115).

TABLE 4:

PAIRED SAMPLES T TEST OF PRETEST AND POST-TEST VOCABULARY LEARNING STRATEGy LEVEL OF THE EXPERIMENTAL GROUP

\begin{tabular}{|c|c|c|c|c|}
\hline Strategies & $\mathrm{N}$ & $\mathrm{t}$ & df & Sig(2-tailed) \\
\hline Memory strategy(Pre-Post) & 35 & -4.084 & 34 & .000 \\
\hline Cognitive Strategy(Pre-Post) & 35 & -4.183 & 34 & .000 \\
\hline Compensation Strategy(Pre-Post) & 35 & -2.713 & 34 & .010 \\
\hline
\end{tabular}

TABLE 5:

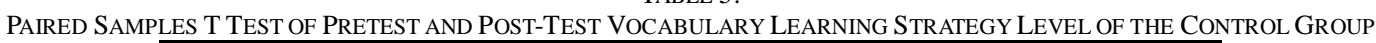

\begin{tabular}{lllll}
\hline Strategies & $\mathrm{N}$ & $\mathrm{t}$ & $\mathrm{df}$ & $\mathrm{Sig}(2$-tailed) \\
\hline Memory strategy(Pre-Post) & 35 & .070 & 34 & .945 \\
Cognitive Strategy(Pre-Post) & 35 & -.591 & 34 & .558 \\
Compensation Strategy(Pre-Post) & 35 & -1.616 & 34 & .115 \\
\hline
\end{tabular}

\section{Discussion}

Information and digital technologies were used in the instruction mode proposed in this research. Firstly, captioned video was introduced into the research and proved to be effective. In his multimedia learning theory Mayer (2001) claims that learning is likely to become more meaningful in multimedia learning environments. The theory also assumes human process information through two channels: one is channel for visual/pictorial/textual/auditory processing; the other is channel for auditory/textual processing. Since each of these two channels has its limited capacity, active learning is based on a collaboration of these channels. (Adler, 1985; Koskinen, Wilson, Bambrell\&Jensema, 1987; Neuman\&Koskinen, 1992). Neuman\&Koskinen (1992) pointed out that captioned video provides a semantically enriched context where the visual and the audio lend meaning to the printed words on the screen. Moreover, according to Krashen's input hypothesis, acquisition takes place when language learners are exposed to adequate comprehensible input (Krashen,1982). Captioned video is a good form of comprehensible input. Secondly digital video camera was used in the research, which not only highly motivated the students but also overcame the barriers of time and space by bringing the students' extracurricular language practice into classroom for teacher's more pertinent comments. This is a creative application of Cohen's SBI theory, which broadens the spatial and time dimension. Thirdly, the proposed instruction mode made good use of corpus and internet to enhance teaching efficiency. For example, vocabularies should be taught with both their grammatical context but also their authentic environment in which a word appears. KWIC function of corpus allows us to meet both of these requirements.

The instruction mode proposed in the research takes the form of task-based collaborative learning. Nunan (1989) pointed out that real life tasks should be assigned to learners in language learning process to develop their real life language competence. Slavin (1996) defines cooperative learning as instructional programs in which students work in small groups to help one another master academic content. Burns and Joyce (1997) said that speakers must manage discrete elements such as turn-taking, rephrasing, providing feedbacks or redirecting. CL is an ideal situation for the students to practice these skills. Frequent use of the language is realized with CL. CL is the opposite of competitive learning, and competitive learning is a typical feature under the traditional exam-centered teaching system. Chinese EFL learners are unwilling to practice English through cooperative learning as a result of long-lasting academic competitive pressures, students. Task-based collaborative learning in this research created necessary circumstances for learners to practice English. One student said in the interview, "In the process of completing the teamwork, we were brainstorming, negotiating in English, which greatly enhanced our collaboration and communication skills."

Students in the research were encouraged to communicate with native English speakers on campus. The students' curiosity, creativity and desire are greatly stimulated. They pour a great amount of time and energy to prepare their topic and rehearse their program in order to "save face" and avoid embarrassment in front of foreigners. This approach not only solved the problem of the students' insufficient language input under the traditional teaching system but also stimulated the students' motivation to practice their productive vocabulary competence. One student described her experience of struggling to start conversations with a foreign teacher in the English corner this way: "At the very beginning, I felt embarrassed when I spoke to the foreigner, my tongue failed me, and I didn't know how to initiate the chatting. I was so nervous that I was fidgeting." After several times of accomplishing such tasks, she described her progress as follows: "Little by little I find that communicating with a foreigner is not as difficult as I imagined and how cool it is to discuss news and cultural differences with a foreigner in English. I made friends with them so that I could have more opportunities to practice my oral English."

\section{CONCLUSION}

Vocabulary is basic building materials of a language. For Chinese EFL Learners the biggest difficulty one first meet 
is how to remember the words efficiently and use them appropriately and correctly in the authentic situation. As an English Teacher, one should research the particular features and cultural background of EFL learners and make full use of the state-of-art information technology to develop the learners' ability to enlarge their vocabulary size, and more importantly to use them in the real communicative world.

\section{REFERENCES}

[1] Adler, R. (1985). Using closed-captioned television in the classroom. In L. Gambrell \& E. McLaughlin (Eds.), New directions in reading: Research and practice. Silver Spring, MD: Yearbook of the State of Maryland International Reading Association.(11-18)

[2] Anderson, R.C., \& Freebody, P. (1981). Vocabulary knowledge. In J. Guthrie (Ed.), Comprehension and teaching: Research reviews. Newark, DE: International Reading Association.(77-177)

[3] Burns, A. and Joyce, H. (1997). Focus on Speaking. Sydney: National Center for English Language Teaching and Research.

[4] Crossword puzzle maker. http://www.armoredpenguin.com/crossword/ (accessed 05/02/2012).

[5] Davies, M. The Corpus of Contemporary American English (COCA): 425 million words, 1990-present.Available online at: http://corpus.byu.edu/coca/ (accessed 05/02/2012)

[6] Davis, F.B. (1944). Fundamental factors in reading comprehension. Psychometrika, 9, 185-197.

[7] Kathleen M. Bailey (2004). Exploring skills. In Nunan. (Ed), Practical English Language Teaching. Beijing: Higher Education Press.(47-66)

[8] Koskinen, P.S., Wilson, R.M., Gambrell, L.B., \& Jensema, C.J. (1987). Using the technology of closed-captioned television to teach reading to handicapped students. Performance Report, United States Department of Education Grant No. G-00-84-30067. Falls Church, VA: National Captioning Institute.

[9] Krashens.(1982). Principles and Practice in Second Language Acquisition. New York: Pergamon Press.

[10] Levy M. (1997). CALL: context and conceptualisation, Oxford: Oxford University Press.

[11] Mayer, R. E. (2001). Multimedia learning. New York: Cambridge University Press.

[12] McCarthy M J. (1990). Vocabulary .Oxford: Oxford University Press.

[13] Meara, P. (1996). The dimensions of lexical competence. In K. Malmkjaer, G. Brown, \& J. Williams (Eds.), Performance and competence in second language acquisition. Cambridge: Cambridge University Press.(35-53)

[14] Neuman, S.B., \& Koskinen, P.S. (1992). Captioned television as comprehensible input: Effects of incidental word learning in context for language minority students. Reading Research Quarterly. 27, 95-106

[15] Nunan, D. (1989). Designing Tasks for the Communicative Classroom. Cambridge: Cambridge University Press.

[16] Oxford, R. (1990). Language Learning Strategies: What Every Teacher Should Know. New York: Newbury House Publishers.

[17] Slavin, R. E. (1996). Cooperative Learning: Theory, Research and Practice. London: Allyn and Bacon.

[18] Teubert, W. (2005). My version of corpus linguistics. International Journal of Corpus Linguistics, 1, 1-13.

[19] Wang Y, Yang J. (2008). A Data-driven Lexical Approach to L2 Lexis Instruction. Shandong Foreign Language Teaching Journal. 125,50-54

[20] Williamson, G. (2009). Type-Token http://www.speech-therapy-information-and-resources.com/type-token-ratio.html (Accessed 31.01.2010. )

Ruixue Ma is currently a lecturer in the School of Foreign Languages, Dalian University of Technology, Dalian, China. Her research interests include EFL teaching, second language acquisition and intercultural communication. 